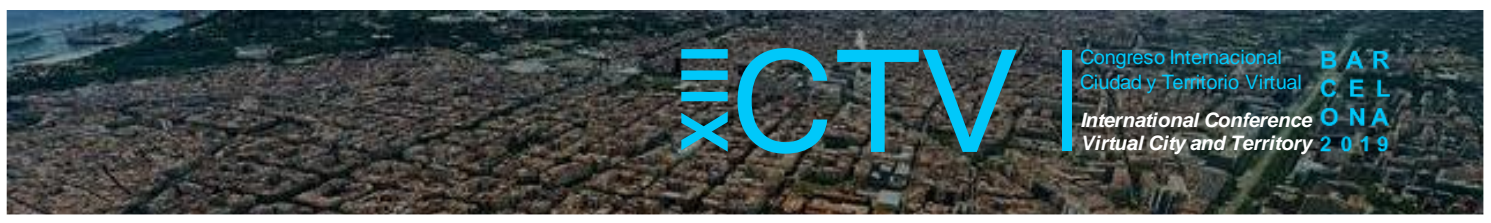

\title{
SISTEMAS DE POLIGENERACIÓN EN EL ÁMBITO URBANO: VENTAJAS E INCONVENIENTES EN LA ACTUALIDAD
}

\author{
Wegener, Moritz ${ }^{1 *}$; Isalgúe, Antonio ${ }^{2}$; Malmquist, Anders ${ }^{3}$; Herrera, Idalberto ${ }^{4}$
}

Remisión inicial: 2019-06-13; Remisión definitiva: 2019-09-17; Publicación: 2019-12-21

Citación: Wegener, M. et al. (2019). Sistemas de poligeneración en el ámbito urbano: ventajas e inconvenientes en la actualidad. En XIII CTV 2019 Proceedings: XIII International Conference on Virtual City and Territory: "Challenges and paradigms of the contemporary city": UPC, Barcelona, October 2-4, 2019. Barcelona: CPSV, 2019, p. 8536. E-ISSN 2604-6512. DOI http://dx.doi.org/10.5821/ctv.8536

Resumen

A causa del agotamiento de los combustibles fósiles y una conciencia creciente sobre las consecuencias de los gases de efecto invernadero, la intención de implementar sistemas de energía más sostenibles y eficientes está aumentando en todo el mundo. Con este objetivo, los mini-sistemas de poligeneración ( $<1 \mathrm{MW}$ de electricidad) de biomasa aspiran a aprovechar al máximo los recursos combustibles, suministrando varios servicios relacionados con la energía como electricidad, calor, refrigeración, agua potable, bioquímicos, etc. Aunque su viabilidad económica y técnica ha sido confirmada en el ámbito rural, existen varios inconvenientes que han frenado su desarrollo en el ámbito urbano.

Basado en dos casos de estudio, apoyados por una revisión profunda de la literatura, se han identificado los mayores obstáculos para introducir mini-sistemas de poligeneración en áreas urbanas. Las dificultades que presentan los sistemas de poligeneración en el ámbito urbano son los altos costes de inversión debido a la necesidad de utilizar tecnologías avanzadas (e.g. intercambiadores de calor, "prime movers" / motores primarios, enfriadores de absorción, etc.), la alta complejidad de los sistemas (su diseño, construcción y funcionamiento, así como en asuntos legales) y a una mayor dificultad para obtener una cantidad suficiente de biomasa.

Además de los factores tecnológicos, los aspectos socio-políticos como la incertidumbre relacionada con la evolución de las tecnologías y la financiación frenan la promoción de sistemas de poligeneración.

Después de identificar estos factores, se proponen soluciones estratégicas que las autoridades municipales pueden implementar para incrementar el uso de mini-sistemas de poligeneración de biomasa. Entre otros, se sugiere implementar procesos más eficientes de recolección y reciclaje de la basura municipal, brindar un impulso financiero a una determinada selección de tecnologías claves para favorecer su crecimiento en el mercado y un mayor apoyo gubernamental para la cooperación entre empresas, ciudadanos y la propia administración.

Palabras Clave: Poligeneración; eficiencia energética; energías renovables

\section{Introducción y objetivos}

Con el aumento constante de la cantidad de gases de efecto invernadero en la atmósfera, es necesaria la creación de herramientas innovadoras y rentables para promover energías renovables (Le Quéré et al., 2018). Mientras que el potencial de recursos fotovoltaicos y eólicos

\footnotetext{
1 Department of Energy Technology, KTH Royal Institute of Technology, Stockholm, Sweden \& Architecture and Energy-School of Architecture, Polytechnic University of Catalonia (UPC), Barcelona, Spain, https://orcid.org/00000003-3070-794X; ${ }^{2}$ School of Architecture, Polytechnic University of Catalonia (UPC), Barcelona, Spain, https://orcid.org/0000-0002-4354-5831; ${ }^{3}$ Department of Energy Technology, KTH Royal Institute of Technology, Stockholm, Sweden, https://orcid.org/0000-0002-4479-344X; ${ }^{4}$ Universidad Central "Marta Abreu" de Las Villas, Santa Clara, Cuba, https://orcid.org/0000-0003-1407-5962. * Correo de contacto: mbgw@kth.se
} 


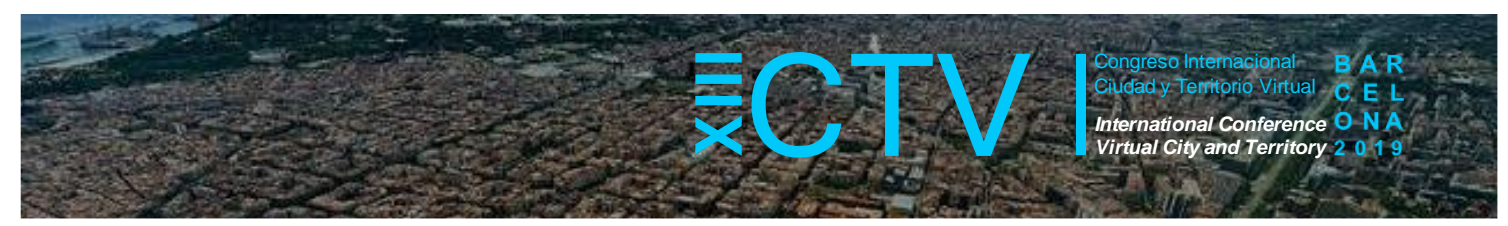

bastaría para satisfacer la demanda media de energía de la humanidad, sus naturalezas fluctuantes dificultan el considerarlos como la solución general. Al ser utilizados de manera eficiente, estos recursos logran satisfacer una parte de la demanda energética, la eléctrica, cuando el consumo energético del sector residencial para servicios térmicos constituye más del $65 \%$ de la demanda energética total, según resultados del proyecto SECH-SPAHOUSEC (Cuchi, Arcas-Abella, \& Pagés-Ramon, 2017; IDAE - Secretaría General, 2011). Alternativamente, se pueden utilizar combustibles como la biomasa, que es de fácil almacenaje y que puede ayudar a satisfacer la demanda eléctrica y térmica durante horas pico, durante la noche y durante períodos de poco viento.

Sin embargo, la cantidad de biomasa disponible para un uso sostenible está limitada. Los sistemas de poligeneración tienen como propósito utilizar esta biomasa limitada de una manera altamente eficiente, ofreciendo aparte de la electricidad otros servicios energéticos, como el agua caliente sanitaria (ACS), el aire acondicionado (AC), la calefacción, etc. Para evitar pérdidas a causa de distancias de distribución largas, especialmente en el flujo de calor, se puede distribuir mini-sistemas de poligeneración, con una capacidad menor a $1 \mathrm{MWe}$ (MW de electricidad). Un esquema de los mini-sistemas de poligeneración de biomasa enfocado en este estudio está presentado en Figura 1 (Wegener, Malmquist, Isalgué, \& Martin, 2018). Se puede separar el funcionamiento de estos sistemas de poligeneración en tres fases:

1. Entrada: Se prepara la biomasa para obtener un combustible de una calidad estandarizada. En general, para biomasa de origen agrícola o más húmeda se usa la conversión bioquímica basada en bacterias, mientras que para biomasa lignocelulósica (i.e. madera) o más seca se usa la conversión termoquímica, basada en la combustión y generación de calor. Se aplican varias tecnologías en esta fase: digestores anaeróbicos, secadores, gasificadores, reactores del proceso Fischer-Tropsch, etc. (Francesco Calise, Dentice, \& Accadia, 2016)

2. Transformación: Consumiendo el biocombustible, los "Prime Movers" generan energía cinética, y con ello electricidad y calor. Como el "Prime mover" representa la conexión entre oferta y demanda, se considera el corazón del sistema (Liu, Shi, \& Fang, 2014). Si la disponibilidad de biomasa es insuficiente, extensiones solares como las placas fotovoltaicas pueden aumentar la potencia disponible en el sistema. Se aplican en esta fase una plétora de tecnologías dentro de las que se incluyen: motores de combustión interna, celdas de combustible, ciclos Rankine con fluidos orgánicos, motores Stirling, micro turbinas, generadores eléctricos de corriente alterna, generadores eléctricos de corriente continua acoplados a los "Prime Movers", etc.

3. Salida: La electricidad y el calor generados se pueden usar de manera directa o almacenar. En lugares cálidos, donde no se requieren grandes cantidades de calor, se puede usar sistemas de refrigeración térmica por adsorción/absorción para aprovechar la energía térmica. Se aplican varias tecnologías para el uso de la electricidad y el calor residual: almacenamiento de energía eléctrica (en baterías de litio, de plomo-acido, de flujo, etc.), monitores y gestores de energía para el hogar, almacenamiento de energía térmica (tanques de agua, materiales del cambio de fase, bombas de calor, etc.), intercambiadores de calor, aparatos de refrigeración (compresión de vapor, absorción, adsorción y desecadores), etc. 


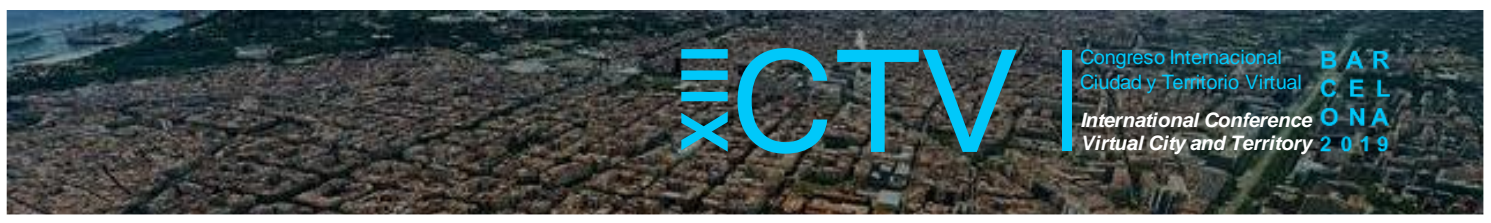

Los sistemas de poligeneración también pueden incluir otras tecnologías para aprovechar la energía térmica (e.g. purificación/destilación de agua con calor, generación de biocombustibles de alta calidad, etc.) pero estas no están consideradas en este estudio.

Figura 1. Sistemas pequeños de poligeneración a base de biomasa

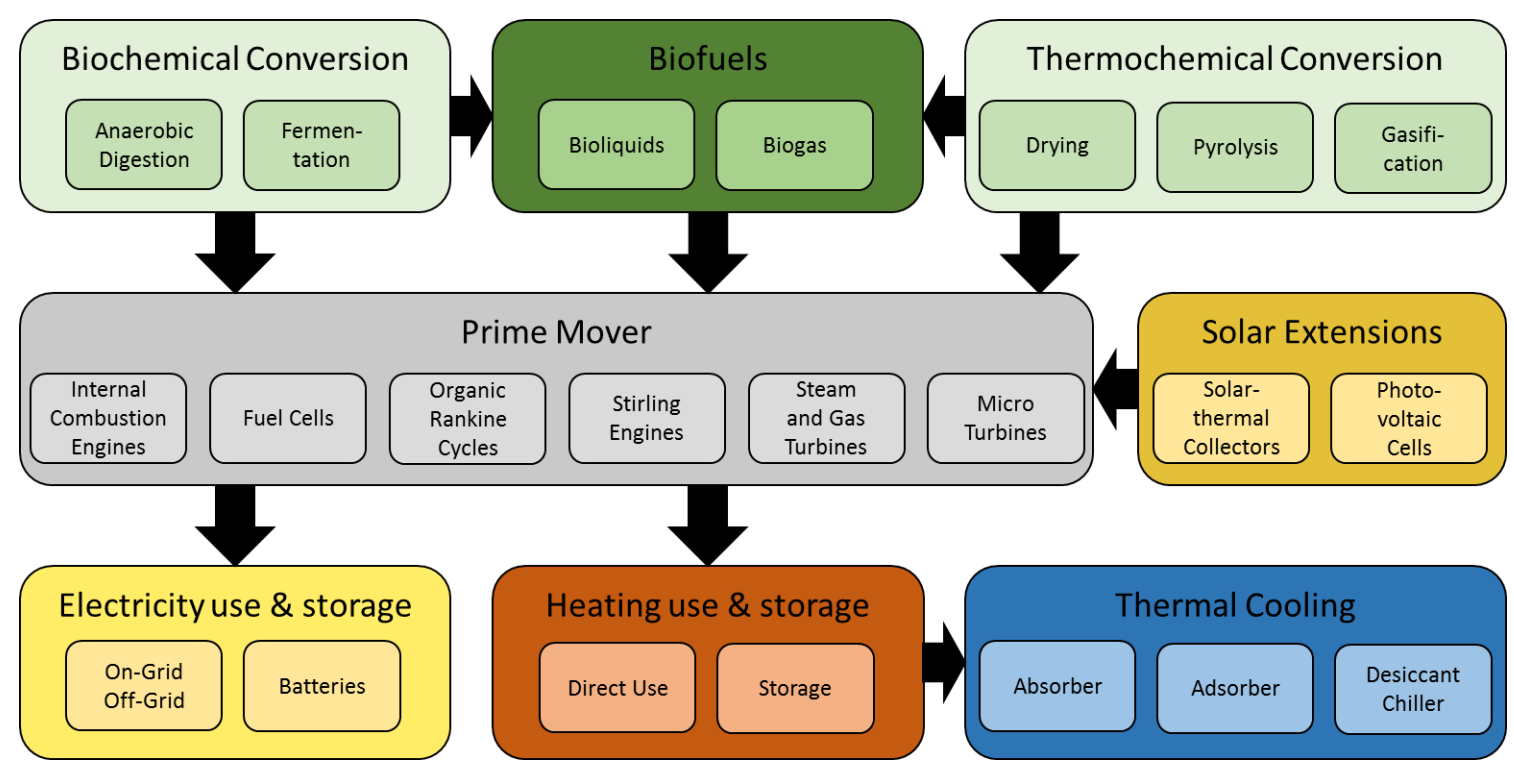

Fuente: Elaboración propia basado en datos de Wegener et al. (Wegener, Malmquist, et al., 2018)

En varios estudios se ha demostrado la viabilidad no solo técnica, sino también económica de los mini-sistemas de poligeneración (Dincer \& Zamfirescu, 2012; Murugan \& Horák, 2016). Se han cuantificado los beneficios con parámetros como los costes totales durante la vida del proyecto, emisiones a lo largo del tiempo de vida del proyecto o la eficiencia energética del sistema. Sin embargo, la mayoría de estos estudios se ha realizado en ámbitos rurales (Khan \& Martin, 2015; Kyriakarakos, Dounis, Rozakis, Arvanitis, \& Papadakis, 2011), cuando en el año 2015 , casi el $70 \%$ de la población de los países occidentales habitaba regiones urbanas y se pronostica un aumento de este porcentaje, especialmente en las regiones en desarrollo, como Asia y África (Urban Europe : statistics on cities, towns and suburbs, 2016).

En áreas urbanas con acceso estable a la red eléctrica dichos sistemas aún no pueden competir económicamente con sistemas convencionales, pero podrían aumentar la resiliencia del sistema eléctrico y disminuir las emisiones de gases contaminante (Wegener, LópezOrdóñez, Isalgue, Malmquist, \& Martin, 2019).

Por lo tanto, en este estudio se identifican los obstáculos y las ventajas de los mini-sistemas de poligeneración de biomasa en el ámbito urbano. Después de presentar diferentes casos de estudio y apoyado por una revisión profunda de la literatura, se comparan los resultados energéticos, ecológicos y económicos, analizando las diferencias y similitudes entre ellos. Usando esta comparación y el Plan Clima de la ciudad de Barcelona (Barcelona, n.d.http://lameva.barcelona.cat/barcelona-pel-clima/sites/default/files/documents/esp plan clima.pdf) se derivan varias recomendaciones, como promover los sistemas de poligeneración en el ámbito urbano. Además, se identifican algunos factores indirectos que pueden influir el desarrollo de 


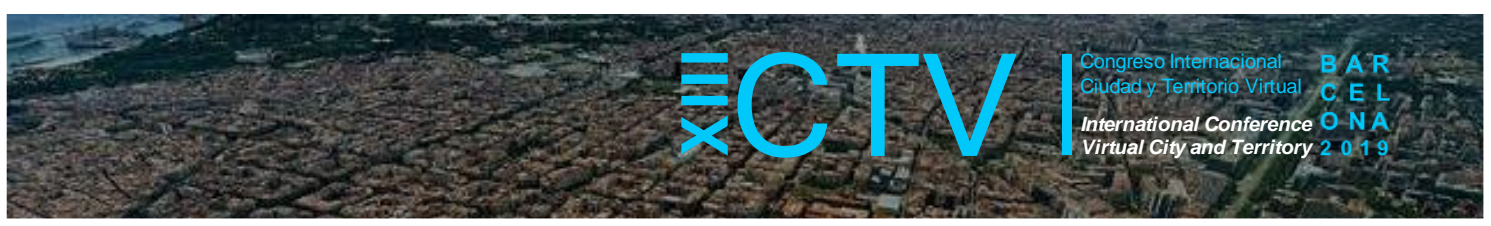

los sistemas de poligeneración que usan biomasa como combustible principal. Finalmente se resumen los resultados del estudio y se presentan las conclusiones finales.

\section{Metodología y datos utilizados}

\subsection{Mini-sistemas de poligeneración en el ámbito urbano}

Un caso urbano que se toma como ejemplo de sistema de poligeneración es el de la ciudad de Hermosillo en México, un resumen se presenta en la Tabla 1.

Tabla 1. Ejemplo de caso urbano: Clima, Consumo y Diseño

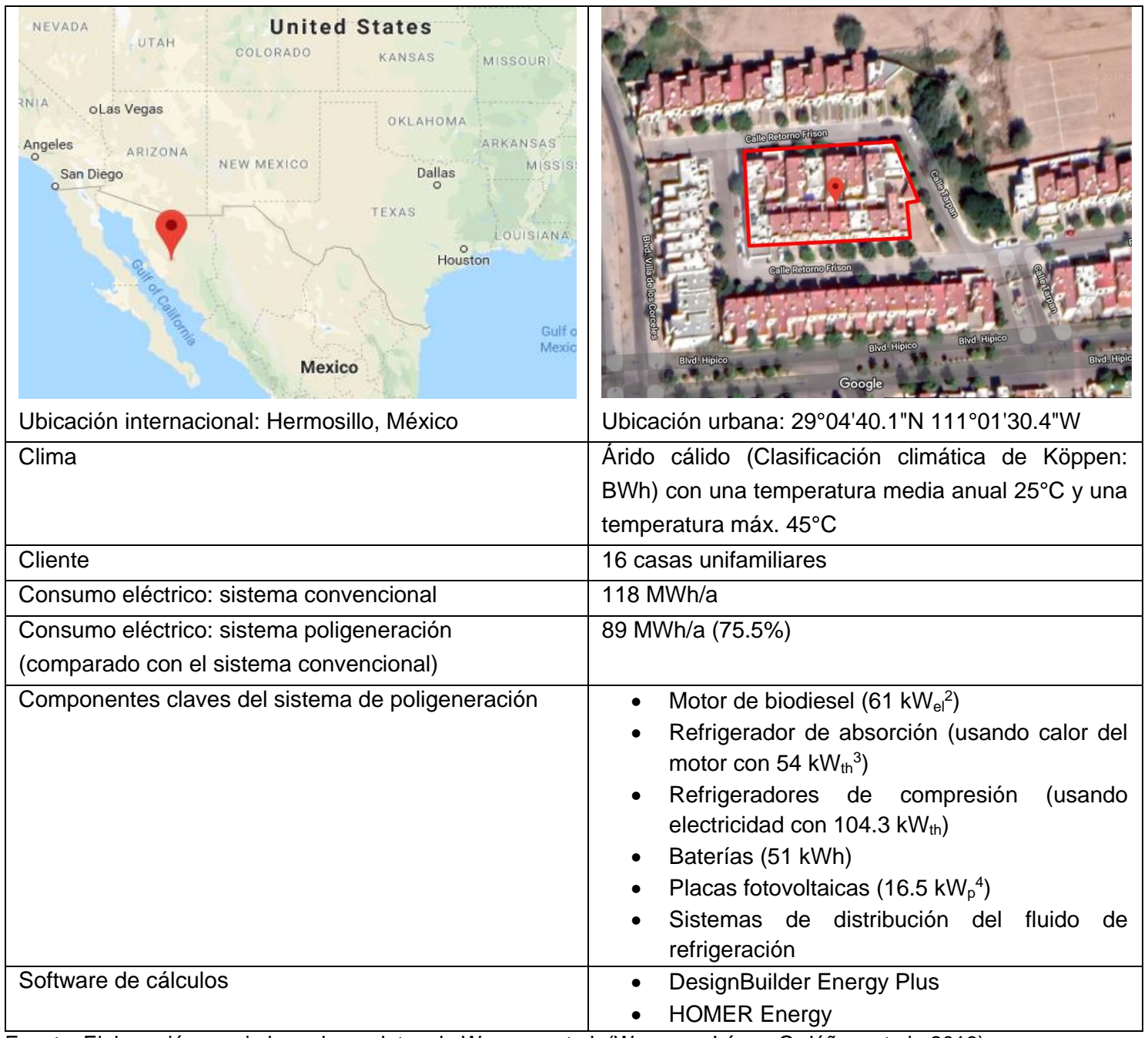

Fuente: Elaboración propia basado en datos de Wegener et al. (Wegener, López-Ordóñez, et al., 2019)

Este sistema permite a los vecinos la oportunidad de desconectarse de la red eléctrica local, logrando una autonomía absoluta. En el caso de referencia, la demanda eléctrica se cubre

\footnotetext{
$2 \mathrm{~kW}_{\mathrm{el}}=$ kilowatt electric output (kilovatio eléctrico)

$3 \mathrm{~kW}_{\mathrm{th}}=$ kilowatt thermal output (kilovatio termicó)

$4 \mathrm{~kW}_{\mathrm{p}}=$ kilowatt peak output (kilovatio pico - bajo condiciones solares óptímas)
} 


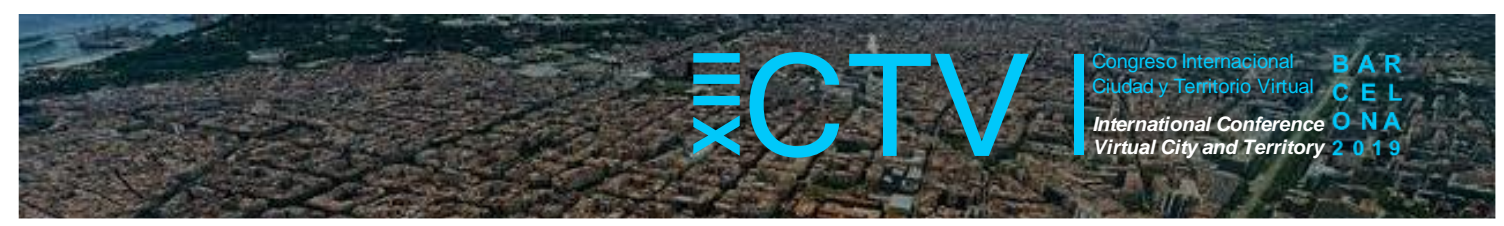

utilizando la energía de la red eléctrica de México, producida en un $80 \%$ a partir de combustibles fósiles, emitiendo grandes cantidades de gases de efecto invernadero. ("Factor de Emisión del Sector Eléctrico Nacional," 2017). Basado en mediciones del consumo eléctrico de una vivienda, se ha calculado la demanda eléctrica y térmica de un bloque de 16 viviendas usando el software DesignBuilder EnergyPlus ("DesignBuilder Software Ltd - Home," n.d.). Luego, considerando esta demanda se ha diseñado un sistema de poligeneración que utiliza biodiesel y energía solar como fuentes primarias de energía (Figura 2).

La energía térmica de la combustión del biodiesel se utiliza en un sistema de refrigeración por absorción para climatización y bajar la demanda eléctrica. Se ha optimizado el sistema por sus costes totales durante la vida del proyecto usando el software HOMER Energy (Homer Energy, 2019). Los resultados obtenidos indican que el sistema puede bajar las emisiones durante la vida del proyecto en más de un $85 \%$ gracias a una mayor eficiencia energética en comparación con el sistema de referencia. Sin embargo, calculado con una vida del proyecto de 20 años, el sistema no podría recuperar la inversión.

Una de las causas es el bajo precio de la energía eléctrica, debido a los subsidios considerables por parte del gobierno mexicano. Un sistema diseñado a una escala más grande podría bajar los costes de inversión per cápita y por tanto presentar una solución más rentable. Además, una solución "smart grid", donde se mantiene la conexión a la red y un intercambio de electricidad podría mejorar la economía del sistema, sin embargo, al mismo tiempo aumentaría la complejidad técnica y podría suponer retos legales con la compañía de distribución de

Figura 2. Esquema del funcionamiento del sistema de poligeneración para Hermosillo energía eléctrica.

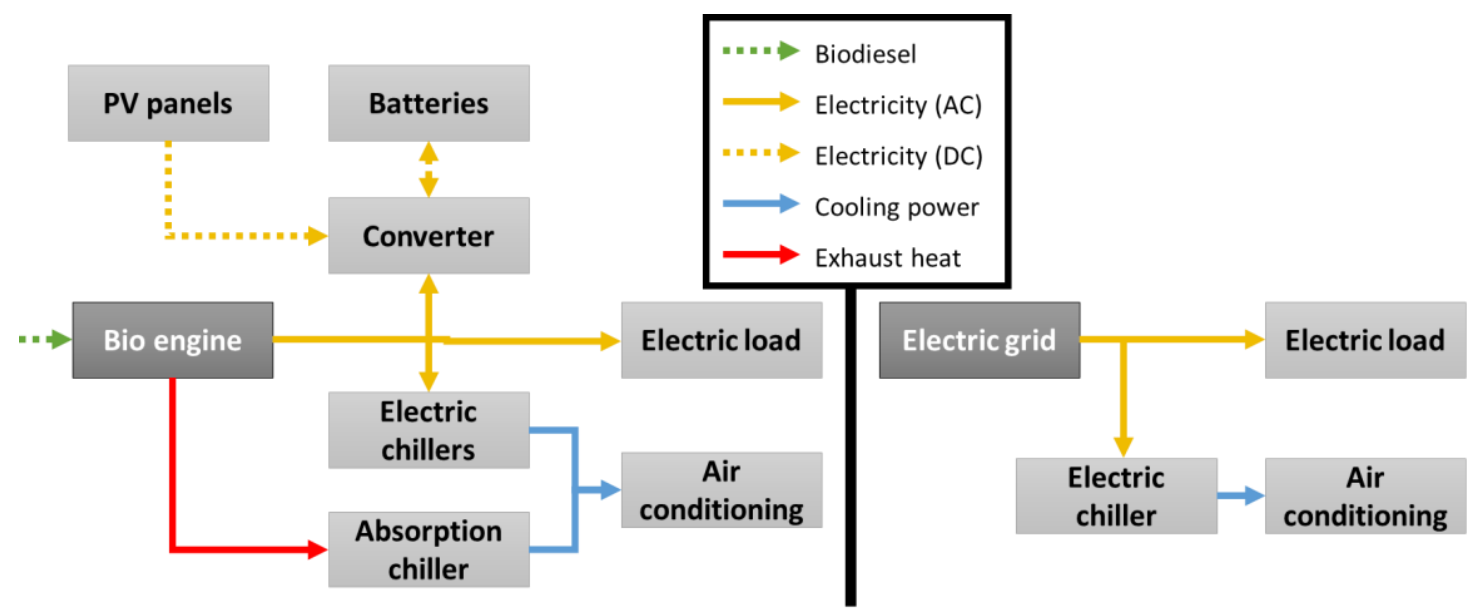

Fuente: Elaboración propia basado en datos de Wegener et al. (Wegener, López-Ordóñez, et al., 2019)

Otros estudios de sistemas de poligeneración muestran resultados similares: Calise et al. (F Calise, Dentice d'Accadia, \& Piacentino, 2015; Francesco Calise, Dentice d'Accadia, \& Piacentino, 2014) han propuesto un sistema de mini-poligeneración utilizando biomasa con combustión directa y placas fotovoltaicas en combinación con colectores solar-térmicos para varios sitios en Nápoles, Italia. 


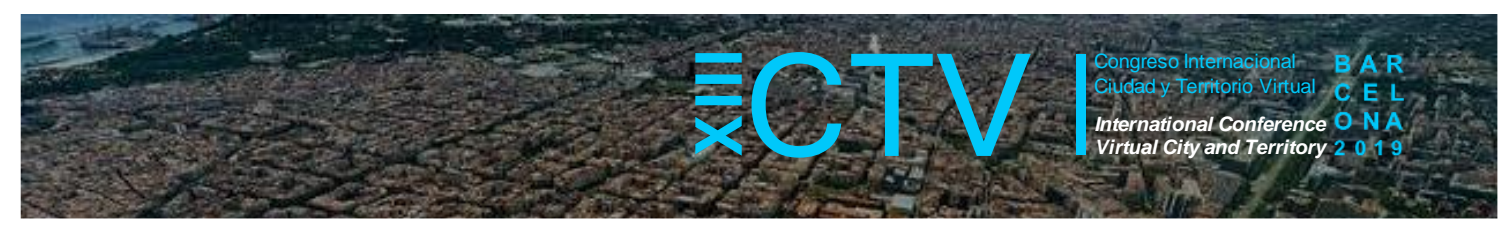

Calcularon varios outputs de los sistemas con comportamientos favorables energéticos y ecológicos. A pesar de ello, concluyen que el sistema propuesto sólo sería económicamente viable en lugares aislados como islas (en sus estudios proponen específicamente Pantelleria, Ischia y las islas Eolias) pero no en el ámbito urbano.

Un mini-sistema de poligeneración diseñado con un motor de $5.5 \mathrm{~kW}_{\mathrm{el}}$ para satisfacer la demanda en un edificio de oficinas ha sido presentado por Marasso et al. (Marrasso, Roselli, Sasso, \& Tariello, 2016). Utilizando el software de modelos de energía TRSNYS y datos sobre la conductividad térmica de los materiales de las fachadas del edificio, se ha estimado la demanda eléctrica y térmica del cliente. El sistema está apoyado por colectores de tubos de vacío, tanques de agua fría y caliente, y un sub-sistema de refrigeración de absorción que permiten generar hasta $18 \mathrm{~kW}_{\text {th }}$ de refrigeración y $43 \mathrm{~kW}_{\text {th }}$ de calor. Después de optimizar el ángulo de inclinación de los colectores solar-térmicos, han calculado varios resultados energéticos, ecológicos y económicos. El sistema puede bajar significativamente el uso de fuentes de energía primaria y disminuir su huella ecológica. Sin embargo, el sistema propuesto es económicamente inviable, ya que presenta un periodo de recuperación de la inversión inaceptable.

\subsection{Mini-sistemas de poligeneración en el ámbito rural}

En la Tabla 2 se resume la información sobre un sistema para un hotel, en un ámbito rural, ubicado en Neil Island, de las islas Andamán en India. Durante el tiempo de la investigación, en el año 2015, un sistema de generadores de diésel satisfacía la demanda eléctrica de la isla entera. Para eso, era necesario transportar grandes cantidades de gasoil a la isla, cuya combustión causaba grandes emisiones de gases del efecto invernadero (Government of Uttarakhand, 2015).

En lugar de utilizar una fuente de energía externa, el sistema de poligeneración tiene el propósito de usar biomasa local, originaria en su mayoría, del cultivo de palmas de coco. El sistema está presentado en la Figura 3. Para transformar la biomasa en un combustible útil para un motor primario se escogió un motor de gas y se propuso un sistema de gasificación.

Aparte de la electricidad generada por el motor, se utiliza la energía térmica con un sistema de absorción para climatización y un sistema de agua caliente sanitaria (ACS). Para no sobrepasar los límites de la biomasa fácilmente accesible, el uso de placas fotovoltaicas y de baterías es necesario para apoyar el sistema. De manera similar al caso urbano presentado anteriormente, el sistema ha sido optimizado por los costes totales de la vida del proyecto usando HOMER Energy.

Aplicando valores de un Análisis del Ciclo de Vida (ACV), las emisiones de gases de efecto invernadero disminuirían un $90 \%$ en comparación con el sistema convencional. A pesar de grandes costes de inversión, el sistema de poligeneración ahorraría al propietario del hotel resort más de medio millón de USD sobre la base de una vida útil del proyecto de 20 años, lo que equivale a casi $30 \%$ de los costes energéticos en este periodo. 


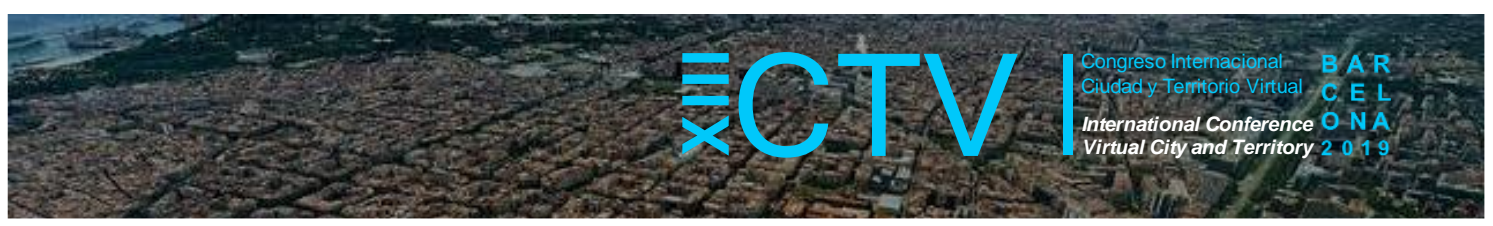

Tabla 2. Ejemplo de caso rural: Clima, Consumo y Diseño

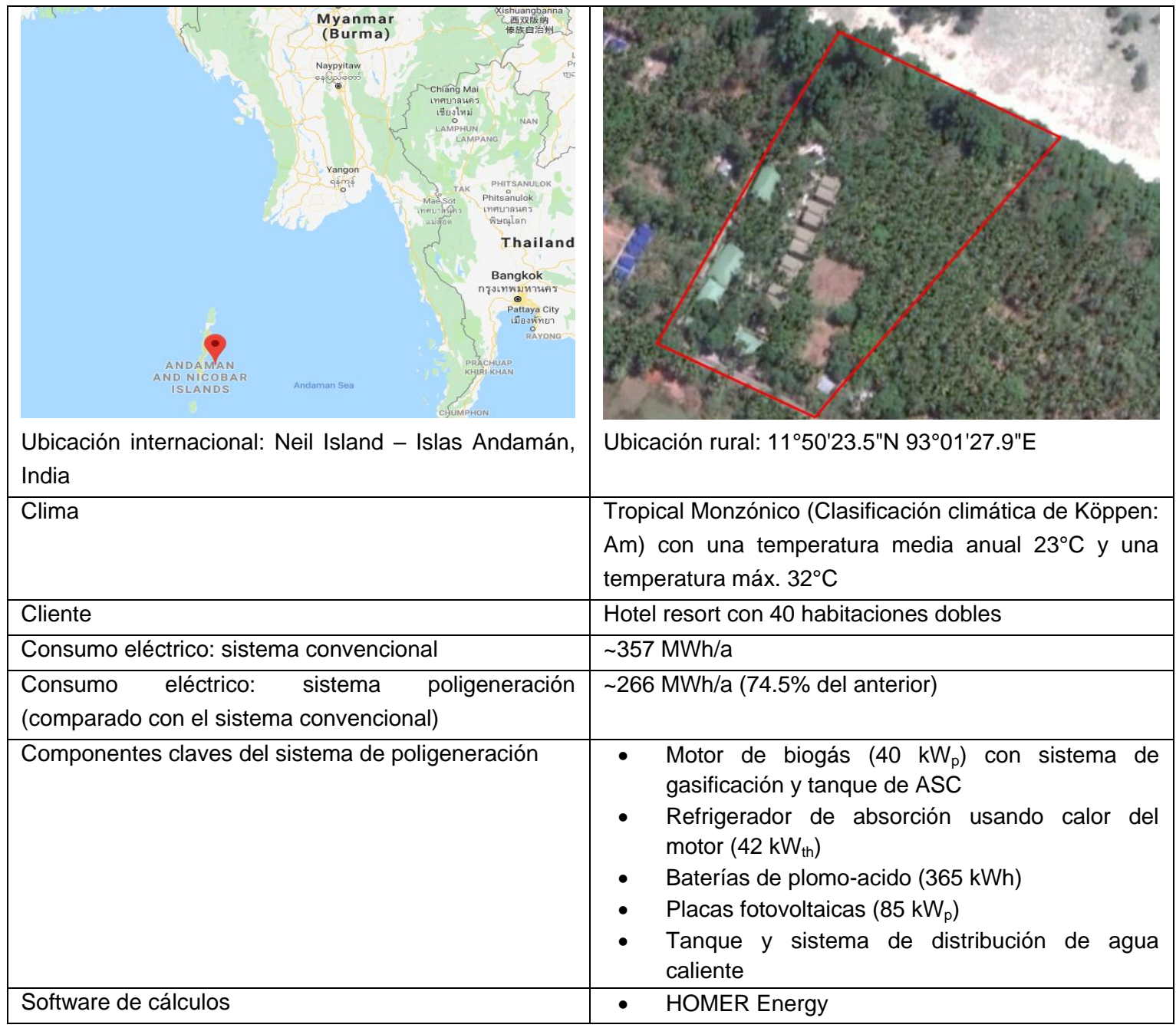

Fuente: Elaboración propia basado en datos de Wegener et al. (Wegener, Isalgué, et al., 2019; Wegener,

Zhang, Isalgué, \& Malmquist, 2018)

Durante el tiempo de la investigación, en el año 2015, un sistema de generadores de diésel satisfacía la demanda eléctrica de la isla entera. Para eso, era necesario transportar grandes cantidades de gasoil a la isla, cuya combustión causaba grandes emisiones de gases del efecto invernadero (Government of Uttarakhand, 2015).

En lugar de utilizar una fuente de energía externa, el sistema de poligeneración tiene el propósito de usar biomasa local, originaria en su mayoría, del cultivo de palmas de coco. El sistema está presentado en la Figura 3. Para transformar la biomasa en un combustible útil para un motor primario se escogió un motor de gas y se propuso un sistema de gasificación.

Aparte de la electricidad generada por el motor, se utiliza la energía térmica con un sistema de absorción para climatización y un sistema de agua caliente sanitaria (ACS). Para no sobrepasar los límites de la biomasa fácilmente accesible, el uso de placas fotovoltaicas y de baterías es necesario para apoyar el sistema. De manera similar al caso urbano presentado anteriormente, el sistema ha sido optimizado por los costes totales de la vida del proyecto 


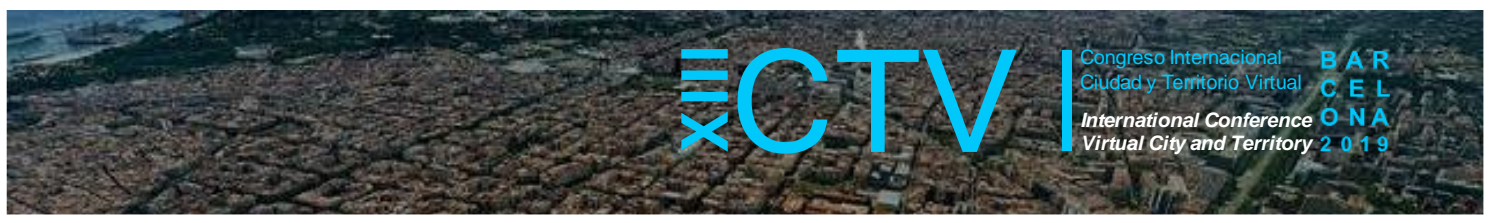

usando HOMER Energy. Aplicando valores de un Análisis del Ciclo de Vida (ACV), las emisiones de gases de efecto invernadero disminuirían un 90\% en comparación con el sistema convencional. A pesar de grandes costes de inversión, el sistema de poligeneración ahorraría al propietario del hotel resort más de medio millón de USD sobre la base de una vida útil del proyecto de 20 años, lo que equivale a casi $30 \%$ de los costes energéticos en este periodo.

Figura 3. Esquema de funcionamiento del sistema de poligeneración de las Islas Andaman

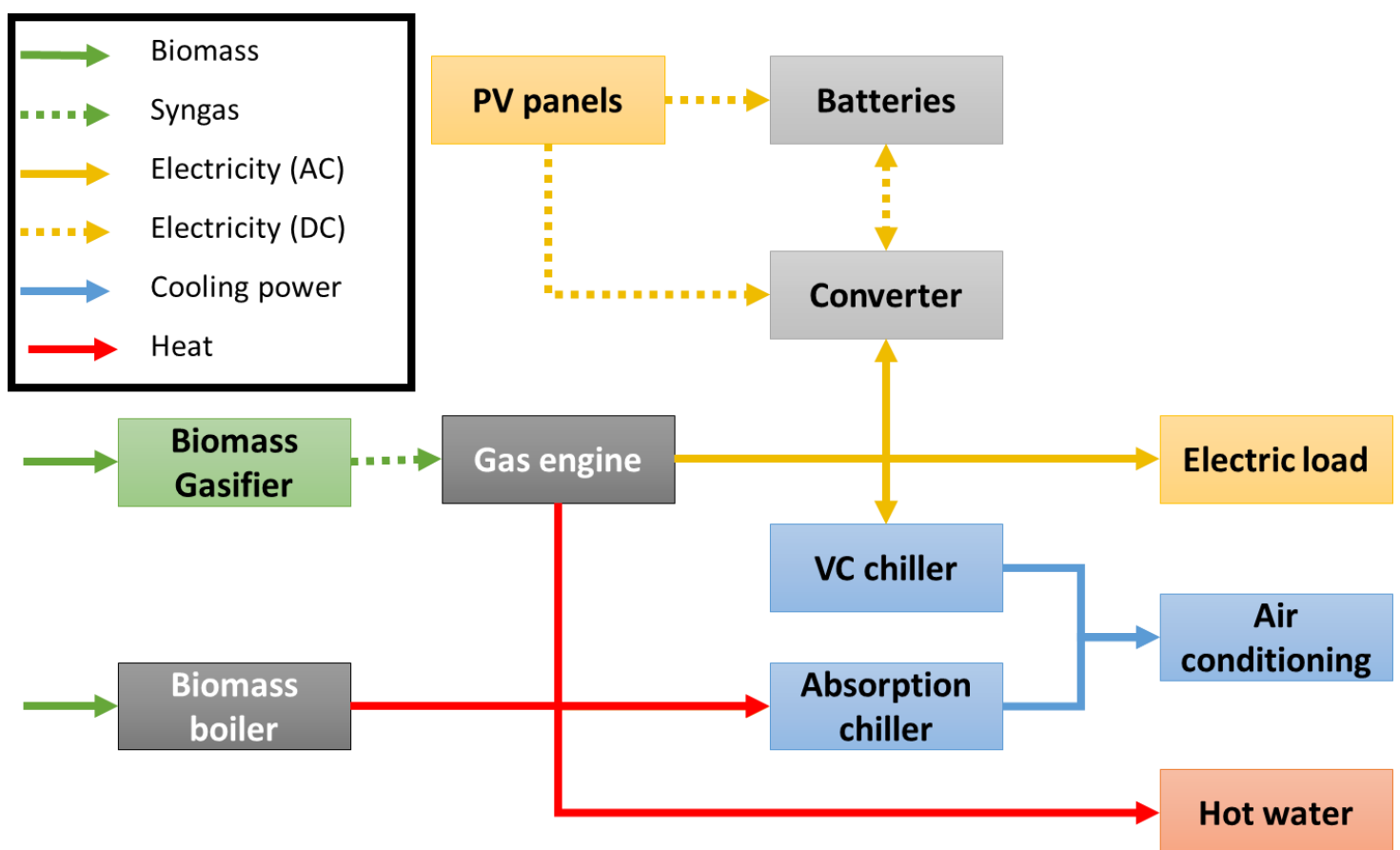

Fuente: Elaboración propia basado en datos de Wegener et al. (Wegener, Isalgué, et al., 2019)

Otros estudios de sistemas rurales de poligeneración muestran resultados similares: Un minisistema de poligeneración de biomasa, que utiliza un ciclo de Rankine orgánico con una capacidad de solo $1.65 \mathrm{~kW}$ e para un bloque de apartamentos en una isla griega, ha sido presentado por Karellas et al. (Karellas \& Braimakis, 2016). A su vez, $50 \mathrm{~m}^{2}$ de colectores cilindro-parabólicos alimentan el sistema para que éste pueda generar $53.5 \mathrm{~kW}_{\text {th }} \mathrm{y}$ el sistema puede generar $5 \mathrm{~kW}_{\text {th }}$ de refrigeración en verano usando un ciclo de compresión de vapor. El sistema muestra un gran potencial en la disminución de emisiones, debido a su mayor eficiencia energética. A pesar del tamaño pequeño del sistema, se ha calculado un periodo de recuperación de la inversión de 7 años indicando una viabilidad económica favorable.

Además de los casos presentados, varios expertos de micro y mini-sistemas de cogeneración y poligeneración de biomasa mencionan que la aplicación más razonable de estos sistemas se ubica en zonas aisladas, como por ejemplo, en regiones rurales del Mediterráneo (González, Riba, Puig, \& Navarro, 2015), regiones de minería en Europa (Paredes-Sánchez, Míguez, Blanco, Rodríguez, \& Collazo, 2019) o en islas (Kyriakarakos et al., 2011). 


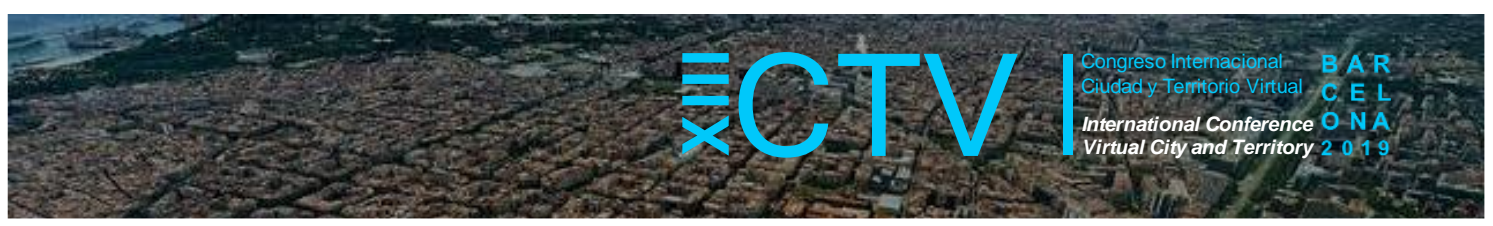

\section{Resultados: Rural vs. Urbano}

\subsection{Similitudes y diferencias}

Después de presentar diferentes casos de estudios rurales y urbanos, se han identificado las similitudes y diferencias entre ellos. Varios parámetros claves de los dos sistemas de poligeneración, comparados con el caso de referencia de los sistemas convencionales, están representados en la Figura 4 . Se puede observar que el comportamiento ecológico de los sistemas de poligeneración es favorable con una reducción de más de $85 \%$ de los gases de efecto invernadero en ambos casos. También el comportamiento energético es similar, con una reducción del consumo eléctrico de casi un $25 \%$ en ambos casos. La reducción en el caso rural está acompañada por una reducción de los costes sobre la vida del proyecto de más de un $30 \%$. Estos sistemas exhiben también otras ventajas económicas con respeto a los sistemas convencionales en estas ubicaciones. Al contrario, en el caso urbano los costes aumentan casi en un $50 \%$ al compararlo con el caso de referencia, indicando que varios factores complican la viabilidad económica.

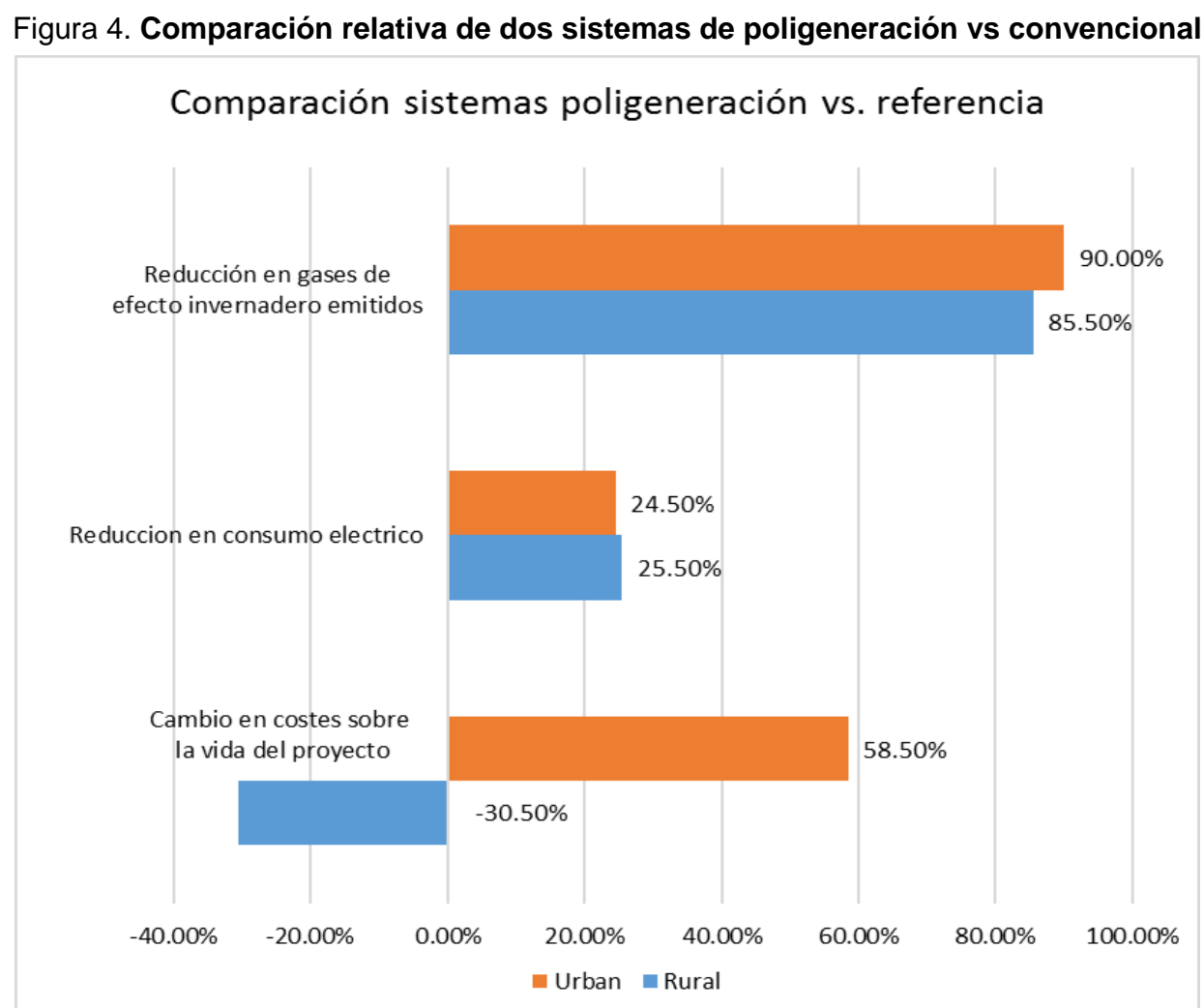

Fuente: Elaboración propia basado en datos de Wegener et al. (Wegener, Isalgué, et al., 2019; Wegener, López-Ordóñez, et al., 2019; Wegener, Zhang, et al., 2018)

Hay que recordar que, en ambos casos los sistemas propuestos son considerablemente más complicados en su diseño, su instalación y su funcionamiento con respecto a los sistemas convencionales debido a un conjunto de tecnologías avanzadas y menos conocidas. Por ello, también la educación y formación de técnicos para operar y mantener los sistemas sería necesario. De todos modos, esto también ofrece oportunidades para la creación de empleos. 


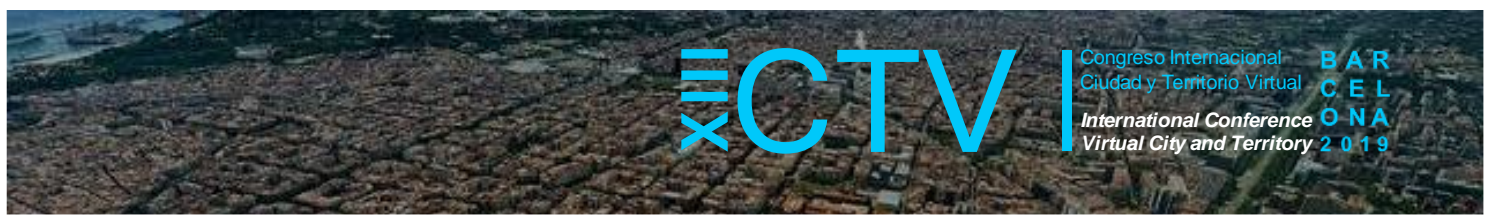

Adicionalmente, en ambos casos son necesarios grandes costes de inversión para construir los sistemas. Estos costes tienen su origen mayormente en la variedad de tecnologías avanzadas de los sistemas, pero también hay que considerar otros gastos por el diseño, el transporte de máquinas y recursos, los seguros, las licencias de construcción etc. De todos modos, al tener en cuenta las grandes ventajas de seguridad y autonomía energética, la creación de empleos y los beneficios ecológicos, las autoridades municipales podrían estar interesadas en facilitar una financiación de los mini-sistemas de poligeneración con biomasa.

Un factor clave para la viabilidad de los sistemas de poligeneración de biomasa es el origen de la biomasa y los costes correspondientes para transformar las fuentes primarias de biomasa en combustibles útiles. En la Tabla 3, se listan los distintos orígenes de estas fuentes de biomasa. Mientras que en el ámbito rural la mayoría de las fuentes tiene su origen en la agricultura, ganadería y silvicultura, en el ámbito urbano el origen de las fuentes de biomasa es mayormente de residuos de viviendas, oficinas e industrias. También se debe tener en cuenta, que casi toda la biomasa disponible en al ámbito urbano ha sido importada efectivamente de un origen rural. Algunas fuentes primarias de biomasa en el ámbito urbano también sufren procesos poco eficientes de recoger, separar y reciclar residuos municipales.

Tabla 3. Fuentes primarias de biomasa

\begin{tabular}{|c|c|}
\hline Rural & Urbano \\
\hline Residuos forestales y desechos de madera. & $\begin{array}{l}\text { Residuos urbanos lignocelulosas / de madera (cajas } \\
\text { de embalaje, paletas, etc. que deben separarse de } \\
\text { los plásticos) }\end{array}$ \\
\hline $\begin{array}{l}\text { Residuos agrícolas (rastrilladores de maíz, tallos de } \\
\text { trigo, vegetales de estación, etc.) }\end{array}$ & Aguas residuales y biogás de aguas residuales \\
\hline Biogás a partir de efluentes ganaderos & Gas de vertedero \\
\hline Cultivos energéticos (pastos o árboles) & $\begin{array}{l}\text { Residuos sólidos municipales } \\
\text { Residuos de procesamiento de alimentos }\end{array}$ \\
\hline
\end{tabular}

Fuente: IRENA - International Renewable Energy Agency ("Renewable Energy Technologies : Cost Analysis Series Volume 1: Biomass for Power Generation," 2012)

No solo las fuentes primarias de biomasa de los mini-sistemas de poligeneración se diferencian en el ámbito rural y en el ámbito urbano, sino también otros factores como se muestra en la Tabla 4. Como en el ámbito rural la densidad de población es por definición más baja, en general la densidad de vegetación per cápita es significativamente más grande y por ello la producción de biomasa per cápita es más grande (Obs. 1). Como se ha mencionado, la biomasa se transporta del ámbito rural al ámbito urbano en forma de comida, muebles, materiales de construcción, etc. (Obs. 2).

Adicionalmente, la población rural se muda continuamente a las ciudades y con ello se traslada la demanda de energía, incluso de biomasa (Obs. 3). Mientras que en países desarrollados la electrificación de casas llega a casi $100 \%$ incluso en el ámbito rural, en países en desarrollo este número es mucho más bajo, por lo tanto, el acceso a fuentes de energía no locales (gasolina, carbón, gas natural o materia nuclear) es más complicado en el ámbito rural (Obs.4). Por ello, los mini-sistemas son tan interesantes en el ámbito rural, por los países en desarrollo. Especialmente en los centros de ciudades, donde varios propietarios poseen pisos dentro de la misma superficie de suelo (Obs. 5). En conjunto con las regulaciones y legislaciones para la sanidad y seguridad de la población urbana (Obs. 6), se complica el proceso de encontrar 


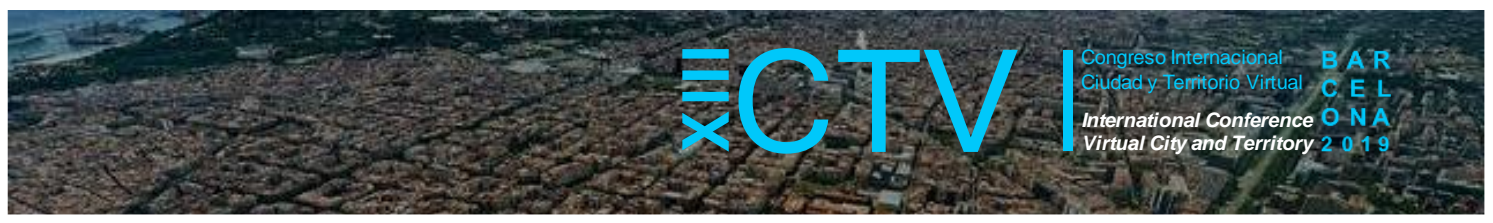

acuerdos entre propietarios, consumidores y administración para construir mini-sistemas de poligeneración.

Mientras que las observaciones 1, 4, 5 y 6 inhiben el desarrollo de mini-sistemas de poligeneración en el ámbito urbano, las observaciones 2 y 3 muestran que existe una oportunidad creciente para su desarrollo al utilizar biomasa como energía renovable.

Tabla 4. Diferencias entre sistemas de poligeneración en el ámbito urbano vs. el ámbito rural

\begin{tabular}{|l|l|l|}
\hline Observación & Ambito rural & Ambito urbano \\
\hline 1 & $\begin{array}{l}\text { Mucha biomasa per cápita y mucha } \\
\text { producción (mucha vegetación) }\end{array}$ & $\begin{array}{l}\text { Poca biomasa per cápita y poca producción } \\
\text { (poca vegetación) }\end{array}$ \\
\hline 2 & Exportación de biomasa al ámbito urbanos & Importación de biomasa del ámbito rural \\
\hline 3 & Demanda bajando (Despoblación) & Demanda creciendo (Urbanización) \\
\hline 4 & Poco acceso a otras fuentes de energía & Varias ofertas de otras fuentes de energía \\
\hline 5 & $\begin{array}{l}\text { Estructuras de propiedad sencillas (cada } \\
\text { entidad posee bastante área) }\end{array}$ & $\begin{array}{l}\text { Estructuras de propiedad complejas (muchas } \\
\text { entidades posen áreas parciales y pequeñas) }\end{array}$ \\
\hline 6 & $\begin{array}{l}\text { Poca regulación de sanidad y seguridad } \\
\text { necesaria }\end{array}$ & $\begin{array}{l}\text { Mucha regulación de sanidad (límites de } \\
\text { emisión, límites de ruido etc.) }\end{array}$ \\
\hline
\end{tabular}

Fuente: Elaboración propia

\subsection{Medidas para fomentar el uso de los sistemas de poligeneración en el ámbito urbano}

La oportunidad de usar biomasa en mini-sistemas de poligeneración en el ámbito urbano para complementar el uso de energías renovables también ha sido estudiada por varias ciudades. Por ejemplo, la ciudad de Barcelona propone en su Plan Clima varias medidas para reducir las emisiones y aumentar el área verde dentro de la ciudad, de las cuales algunas apoyan el uso de mini-sistemas de poligeneración (Barcelona, n.d.). Estas medidas o líneas de acción se pueden catalogar en dos grupos: aumentar la biomasa y los residuos disponibles en el área urbana (grupo 1) y aumentar la investigación y conciencia sobre las energías renovables incluyendo mini-sistemas de poligeneración (grupo 2):

\section{- $\quad$ Crear más combustible de biomasa y residuos municipales:}

1. Varias líneas de acción consideran la economía circular, la cual se enfoca en el reciclaje y la reutilización de cada tipo de residuos urbanos Plan Clima. Con el fomento de sistemas de depósito, devolución y retorno se obtienen más residuos y mejor categorizados, de los cuales muchos pueden servir como combustible para los minisistemas de poligeneración.

2. Los proyectos de soberanía alimentaria (línea de acción 15) aspiran a promover productos de proximidad, ecológicos y saludables. Para eso, la ciudad de Barcelona planea desarrollar una mayor área para la producción y un mayor número de circuitos de alimentación de proximidad. Además, se estudian diferentes maneras de concienciar a la ciudadanía sobre la importancia de una alimentación sana y sostenible. En combinación con la economía circular, lo cual implica más residuos vegetales que son utilizables en una escala local para sistemas de poligeneración.

3. Proyectos de biodiversidad urbana con más parques y micro-jardines aumentarían la biomasa verde (Línea de acción 7): Por razones como lograr una regulación hídrica y micro-climática, mejorar la calidad del aire y la aportación de alimentos, se pretende un aumento de $1,6 \mathrm{~km}^{2}$ de área verde en la ciudad. Eso también implica un aumento de biomasa, que se puede recoger y utilizar para mini-sistemas de biomasa. 


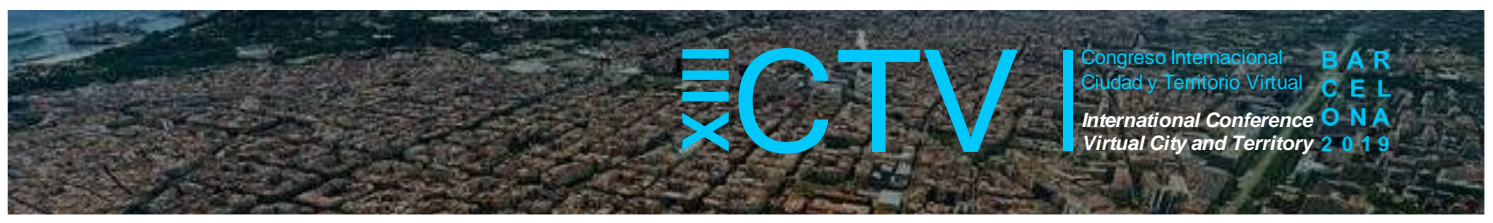

- Promover la energía renovable de biomasa, la conciencia y la investigación:

1. Para conectar a los ciudadanos de una manera directa con los productores de energías renovables, Barcelona ha creado una comercializadora energética municipal: Barcelona Energía (líneas de acción 2, 4, 5 y 9). Con esta comercializadora pública, los ciudadanos reciben energía $100 \%$ renovable, producida regionalmente sin intermediarios privados.

2. Para que los mini-sistemas de poligeneración tengan éxito, es esencial que se dé un mayor avance de las tecnologías mencionadas en la primera sección "Introducción y objetivos". Para lograrlo, los proyectos de Open Data permiten un intercambio de información y resultados de varios sistemas y programas (línea de acción 18). Además, esto también permite identificar la variación del rendimiento de los mini-sistemas bajo diferentes periodos y como cambian con el cambio climático. La ciudad de Barcelona también promueve el desarrollo de mini-sistemas de poligeneración mediante proyectos de investigación que se encuentran directamente relacionados a las tecnologías relevantes para éste desarrollo.

3. El apoyo se concentra no solo en el ámbito académico, sino también en el ámbito industrial, y aspira a fortalecer la cooperación entre los dos mediante proyectos innovadores (línea de acción 18). Para lograrlo, la ciudad de Barcelona impulsa sistemas de autoproducción y autoconsumo para empresas e institutos con apoyos financieros y servicios de consultaría.

4. Aunque Barcelona es una ciudad pionera en la transición energética dentro de España, otras ciudades pueden compartir experiencias dentro de varias áreas, donde Barcelona todavía no se ha desarrollado lo suficiente (línea de acción 18). Por otra parte, Barcelona puede ofrecer sus experiencias y buenas prácticas a otras ciudades. Por lo tanto, la participación en redes de ciudades nacionales e internacionales presenta otra medida para avanzar el desarrollo de energías renovables, incluyendo los minisistemas de poligeneración.

5. No solo el apoyo de los profesionales es clave para penetrar en el mercado con los mini-sistemas de poligeneración, sino también se requiere el apoyo de toda la ciudadanía. Para obtenerlo, es necesaria la creación de puntos de información en los que se eduque a la población sobre las ventajas e inconvenientes de las energías renovables y del uso de mini-sistemas de poligeneración (línea de acción 16).

\subsection{Factores indirectos}

Aparte de las medidas directas que las ciudades pueden tomar, existen varios factores indirectos que también influyen en el desarrollo de los mini-sistemas de poligeneración con biomasa en el ámbito urbano. Estos factores tienen su origen mayormente en las decisiones de la comunidad más amplia, el estado nacional y/o las organizaciones internacionales a las cuales pertenece el estado (e.g. la Unión Europea, la OMS, el FMI, la OPEP etc.) y de desarrollos globales de las tecnologías claves:

1. Últimamente, cada tipo de energía renovable compite directamente con el sistema convencional y, por lo tanto, con los combustibles fósiles. Por eso, los precios de petróleo y gas natural condicionan fuertemente la viabilidad económica de cada sistema. Cuando se consideraba tradicionalmente un precio bajo favorable para el crecimiento de la economía, por otro lado, no se puede negar la influencia de un consumo excesivo de combustibles fósiles sobre el clima y la salud humana. Estos precios son por fin altamente dependientes de la política internacional que persiguen 


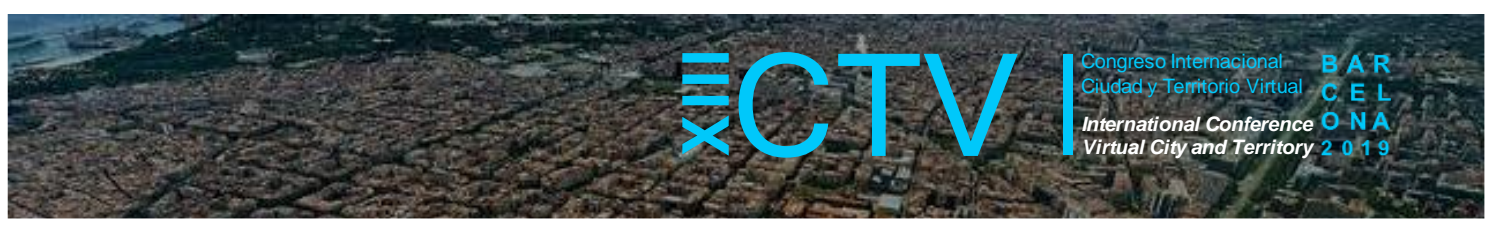

los países exportadores de petróleo (como los miembros de la OPEP, la Federación de Rusia, Canadá, etc.) tanto como la política nacional que dicta los impuestos y subsidios para los combustibles fósiles. Entonces, una medida lógica para disminuir el uso de combustibles fósiles y favorecer el uso de energías renovables es eliminar cualquier subsidio para los combustibles fósiles (Worrall \& Runkel, 2017).

2. Pero los mini-sistemas de poligeneración de biomasa no solo compiten con los sistemas convencionales, sino también con otras tecnologías de energías renovables. En el uso urbano, la energía solar fotovoltaica ha experimentado una pequeña revolución debida, sobre todo, a grandes avances tecnológicos que han generado una importante reducción en los costes. Esto no quiere decir que no hay espacio de mejora, por lo que se genera una oportunidad para los mini-sistemas de poligeneración a complementar otras tecnologías de generación de energía más sostenible.

3. Alejándose de la idea de los sistemas fijos en un único punto, varios investigadores proponen mini-sistemas de poligeneración con biomasa que sean flexibles (Ulloa, Eguía, et al., 2013; Ulloa, Porteiro, et al., 2013) (Paleta, Pina, \& Santos Silva, 2014). Con un sistema compacto montado en un contenedor de envió estándar, o en una caravana, se puede utilizar la tecnología de poligeneración en cualquier sitio que se desee. Esto permite romper los límites del ámbito urbano o rural y aprovechar los sistemas de poligeneración de manera flexible. A pesar de que estos sistemas móviles solo presentan una solución para un determinado nicho de mercado, también influyen en el mercado general.

\section{Conclusiones}

Los resultados demuestran que los mini-sistemas de poligeneración con biomasa representan una alternativa más sostenible que los sistemas convencionales usando menos energía primaria y emitiendo menos gases de efecto invernadero. Mientras que en el ámbito rural ya representan una solución favorable, en el ámbito urbano aún no pueden competir económicamente, esto se debe a diferentes factores tecnológicos y socio-políticos. La identificación de estos factores es el primer paso para diseñar las estrategias de un futuro desarrollo de los sistemas de poligeneración en ciudades. Algunos de estos factores incluyen una menor cantidad de biomasa generada per cápita, una mayor competencia con otras fuentes de energía, así como la existencia de complicaciones de carácter legal, que se deben a regulaciones más estrictas y a un mayor número de propietarios por área en zonas urbanas.

Usando el ejemplo del Plan Clima de la ciudad de Barcelona, se han identificado diversas medidas que indican como las administraciones municipales pueden apoyar el desarrollo y la distribución de mini-sistemas de poligeneración con biomasa. Para aumentar la cantidad de biomasa disponible en la ciudad, se recomienda implementar procesos más eficientes de recolección (recogida selectiva) y reciclaje de la basura municipal, aumentar el uso de productos alimentarios de proximidad y mejorar la biodiversidad metropolitana mediante un mayor número de parques y micro-jardines. Además, otras medidas indirectas, como avanzar en la investigación de tecnologías relevantes, apoyar estructuras para el intercambio de información (Open Data) y de buenas prácticas tanto como reforzar los proyectos entre las instituciones académicas y las empresas pueden facilitar la penetración de los mini-sistemas de poligeneración en el mercado. 


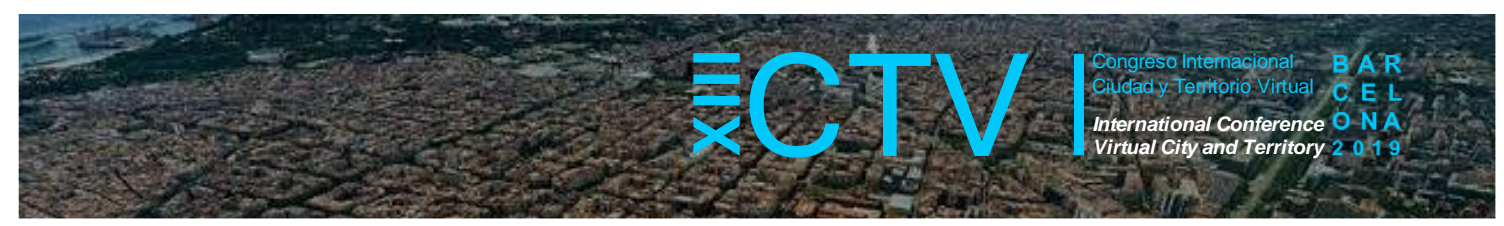

Los sistemas de poligeneración, en combinación con otras tecnologías de energías renovables (e.g. energía solar, energía eólica, energía hidráulica etc.), pueden contribuir a la transición energética y prevenir la emisión de grandes cantidades de gases de efecto invernadero.

Agradecimientos: Esta investigación se ha desarrollado en colaboración entre UPC (Universitat Politècnica de Catalunya) y KTH (Royal Institute of Technology), a través de un Erasmus Mundus Joint Doctoral Programme SELECT+, del que se agradece el soporte. A. I. agradece el soporte del proyecto español MICINN MOET_BIA2016-77675-R.

Acknowledgements: This research has been conducted in collaboration between UPC (Universitat Politècnica de Catalunya) and KTH Royal Institute of Technology, funded through the Erasmus Mundus Joint Doctoral Programme SELECT+, the support of which is gratefully acknowledged. A. I. acknowledges the Spanish project MOET_BIA2016-77675-R.

Contribuciones de los autores: M.W. ha llevado la iniciativa en el desarrollo del texto, a partir de trabajo encaminado a la obtención del Doctorado. Los demás autores han realizado sugerencias, ampliado el texto, y revisado y aprobado el texto final.

Conflicto de Intereses: Los autores declaran que no hay conflictos de intereses.

\section{Bibliografía}

Barcelona. (n.d.). Plan Clima 2018. Retrieved from http://lameva.barcelona.cat/barcelona-pelclima/sites/default/files/documents/esp_plan_clima.pdf

Calise, F, Dentice d'Accadia, M., \& Piacentino, A. (2015). Exergetic and exergoeconomic analysis of a renewable polygeneration system and viability study for small isolated communities. Energy, 92, 290-307. https://doi.org/10.1016/j.energy.2015.03.056

Calise, Francesco, Dentice d'Accadia, M., \& Piacentino, A. (2014). A novel solar trigeneration system integrating PVT (photovoltaic/thermal collectors) and SW (seawater) desalination: Dynamic simulation and economic assessment. Energy, 67, 129-148. https://doi.org/10.1016/j.energy.2013.12.060

Calise, Francesco, Dentice, M., \& Accadia, D. '. (2016). Simulation of Polygeneration Systems. https://doi.org/10.3390/en9110925

Cuchi, A., Arcas-Abella, J., \& Pagés-Ramon, A. (2017). Estudio de la distribución del consumo energético residencial para calefacción en España. Retrieved from https://www.fomento.gob.es/NR/rdonlyres/53E31468-1B09-4123-A05B-

OFBEB86B858E/149686/201804_Estudio_distribucion_consumo_energetico_res.pdf

DesignBuilder Software Ltd - Home. (n.d.). Retrieved from https://designbuilder.co.uk//

Dincer, I., \& Zamfirescu, C. (2012). Renewable-energy-based multigeneration systems. International Journal of Energy Research, 36(15), 1403-1415. https://doi.org/10.1002/er.2882

Factor de Emisión del Sector Eléctrico Nacional. (2017). Retrieved from https://www.gob.mx/cms/uploads/attachment/file/304573/Factor_de_Emisi_n_del_Sector_El_ctr ico_Nacional_1.pdf 


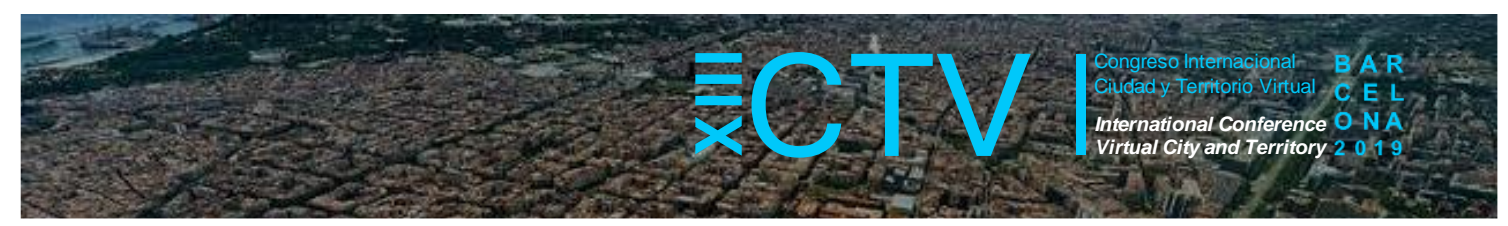

González, A., Riba, J.-R., Puig, R., \& Navarro, P. (2015). Review of micro- and small-scale technologies to produce electricity and heat from Mediterranean forests' wood chips. Renewable and Sustainable Energy Reviews, 43, 143-155. Retrieved from https://www.sciencedirect.com/science/article/pii/S1364032114009447

Government of Uttarakhand. (2015). $24 \times 7$ Power for All Uttarakhand. Retrieved from https://powermin.nic.in/sites/default/files/uploads/joint_initiative_of_govt_of_india_and_andman _nicobar.pdf

Homer Energy. (2019). HOMER - Hybrid Renewable and Distributed Generation System Design Software. Retrieved from https://www.homerenergy.com/support/docs/3.10/glossary.html

IDAE - Secretaría General. (2011). Proyecto SECH-SPAHOUSEC - Análisis del consumo energético del sector residencial en España. Retrieved from https://www.idae.es/uploads/documentos/documentos_Informe_SPAHOUSEC_ACC_f68291a3.pdf

Karellas, S., \& Braimakis, K. (2016). Energy-exergy analysis and economic investigation of a cogeneration and trigeneration ORC-VCC hybrid system utilizing biomass fuel and solar power. Energy Conversion and Management, 107(July 2014), 103-113. DOI https://doi.org/10.1016/j.enconman.2015.06.080

Khan, E. U., \& Martin, A. R. (2015). Optimization of hybrid renewable energy polygeneration system with membrane distillation for rural households in Bangladesh. Energy, 93, 1116-1127. https://doi.org/10.1016/j.energy.2015.09.109

Kyriakarakos, G., Dounis, A. I., Rozakis, S., Arvanitis, K. G., \& Papadakis, G. (2011). Polygeneration microgrids: A viable solution in remote areas for supplying power, potable water and hydrogen as transportation fuel. Applied Energy, 88(12), 4517-452. DOI. https://doi.org/10.1016/j.apenergy.2011.05.038

Le Quéré, C., Andrew, R. M., Friedlingstein, P., Sitch, S., Hauck, J., Pongratz, J., ... Canadell, J. G. (2018). Global carbon budget 2018. Earth System Science Data, 10, 2141-2194. DOI https://doi.org/10.5194/essd-10-2141-2018

Liu, M., Shi, Y., \& Fang, F. (2014). Combined cooling, heating and power systems: A survey. Renewable and Sustainable Energy Reviews, 35, 1-22. DOI https://doi.org/10.1016/j.rser.2014.03.054

Marrasso, E., Roselli, C., Sasso, M., \& Tariello, F. (2016). Analysis of a hybrid solar-assisted trigeneration system. Energies, 9(9). DOI https://doi.org/10.3390/en9090705

Murugan, S., \& Horák, B. (2016). Tri and polygeneration systems - A review. Renewable and Sustainable Energy Reviews. DOI https://doi.org/10.1016/j.rser.2016.01.127

Paleta, R., Pina, A., \& Santos Silva, C. A. (2014). Polygeneration Energy Container: Designing and Testing Energy Services for Remote Developing Communities. IEEE Transactions on Sustainable Energy, 5(4), 1348-1355. DOI https://doi.org/10.1109/TSTE.2014.2308017

Paredes-Sánchez, J. P., Míguez, J. L., Blanco, D., Rodríguez, M. A., \& Collazo, J. (2019). Assessment of micro-cogeneration network in European mining areas: A prototype system. Energy, 174, 350-358. DOI https://doi.org/10.1016/J.ENERGY.2019.02.146 


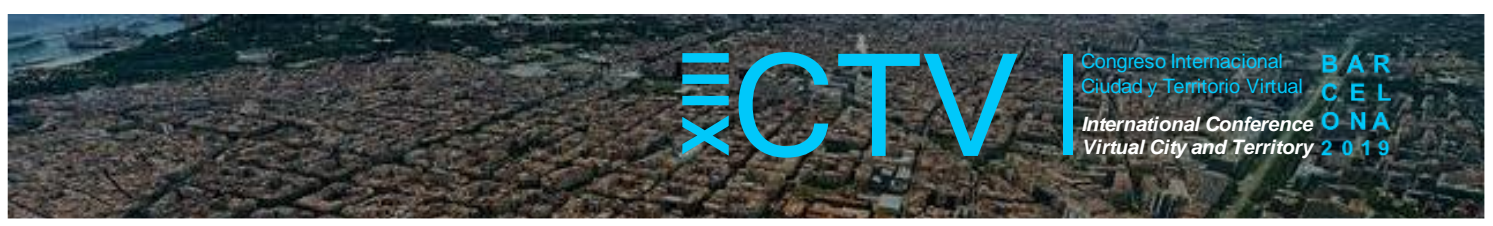

Renewable Energy Technologies: Cost Analysis Series - Volume 1: Biomass for Power Generation. (2012). IRENA- International Renewable Energy Agency.

Ulloa, C., Eguía, P., Miguez, J. L., Porteiro, J., Pousada-Carballo, J. M., \& Cacabelos, A. (2013). Feasibility of using a Stirling engine-based micro-CHP to provide heat and electricity to a recreational sailing boat in different European ports. Applied Thermal Engineering, 59(1-2), 414-424. DOI https://doi.org/10.1016/J.APPLTHERMALENG.2013.06.015

Ulloa, C., Porteiro, J., Eguía, P., Pousada-Carballo, J., Ulloa, C., Porteiro, J., ... PousadaCarballo, J. M. (2013). Application Model for a Stirling Engine Micro-Generation System in Caravans in Different European Locations. Energies, 6(2), 717-732. DOI https://doi.org/10.3390/en6020717

Urban Europe: statistics on cities, towns and suburbs. (2016). Retrieved from https://ec.europa.eu/eurostat/en/web/products-statistical-books/-/KS-01-16-691

Wegener, M., Isalgué, A., Malmquist, A., Martin, A., Wegener, M., Isalgué, A., ... Martin, A. (2019). 3E-Analysis of a Bio-Solar CCHP System for the Andaman Islands, India-A Case Study. Energies, 12(6), 1113. DOI https://doi.org/10.3390/en12061113

Wegener, M., López-Ordóñez, C., Isalgue, A., Malmquist, A., \& Martin, A. (2019). How much does it cost to go off-grid with renewables? A case study of a polygeneration system for a neighbourhood in. In A. C. and L. C. J. J.Littlewood, R.J.Howlett (Ed.), Seb 2019 (pp. 1-10). Budapest, Hungary.

Wegener, M., Malmquist, A., Isalgué, A., \& Martin, A. (2018). Biomass-fired combined cooling, heating and power for small scale applications - A review. Renewable and Sustainable Energy Reviews, 96, 392-410. DOI https://doi.org/10.1016/j.rser.2018.07.044

Wegener, M., Zhang, Y., Isalgué, A., \& Malmquist, A. (2018). Economic and ecologic assessment of a biomass-based CHP system for a hotel resort on the Andaman Islands, India. In World Renewable Energy Congress 2018. Kingston upon Thames, London: Springer.

Worrall, L., \& Runkel, M. (2017). Supervisando las ayudas a los combustibles fósiles en Europa: España. Retrieved from https://ent.cat/wp-content/uploads/2017/10/Informe_Ayudasfosiles.pdf 